\title{
Measure the Bulk Etch Rate Using the Time-Diameter Method
}

\author{
Hussein A. Ahmed, Alan S. Said Ahmad, Ari A. Mohammed \\ Department of Physics, Faculty of Science, University of Zakho, Duhok, Iraq \\ Email: pahmedhussein@gmail.com
}

Received 5 March 2015; accepted 28 March 2015; published 31 March 2015

Copyright (C) 2015 by authors and Scientific Research Publishing Inc.

This work is licensed under the Creative Commons Attribution International License (CC BY). http://creativecommons.org/licenses/by/4.0/

c) (i) Open Access

\begin{abstract}
The present work measured the bulk etch rate $\left(V_{B}\right)$ of solid state nuclear track detector by taking the diameter time measurement of alpha particle in CR-39 detector. The values of the track diameter have been found by using TRACK-TEST program from Yu et al. function and Brun et al. function with different energies of alpha particles. The results showed that the time-diameter $(t-d)$ method gave good results of the bulk etch rate $\left(V_{B}\right)$ and these values were $(1.705$ and 1.72$) \mu \mathrm{m} \cdot \mathrm{hr}^{-1}$. They showed good agreement with the values measured by using the other methods, and it was a simple method because it required getting diameters of the tracks in the detector with the etching time.
\end{abstract}

\section{Keywords}

Bulk Etch Rate, CR-39, Diameter-Time Measurements, Nuclear Track Detector (NTD)

\section{Introduction}

Solid State Nuclear Track Detectors (SSNTDs) are extensively used for registering nuclear tracks (Fleischer, Price and Walker, 1975) [1]. CR-39 is one of the most commonly used as SSNTDs. CR-39 is transparent in visible spectrum and combines an exceptional range of qualities which are not available in other SSNTDS [2].

A track is created in a SSNTD when an alpha particle hits the detector's surface. The formation of the track is characterized by the value of detector registration sensitivity $(V=V t / V b)$, where $(V t)$ is the track etchrate, which is the removed layers of damaged surface of SSNTD (alpha-particle's hitting position) per unit time and $(V b)$ is the bulk etch rate. $V b$ is the rate of removing layers of the undamaged surface of SSNTD. $V b$ varies due to the SSNTD's chemical composition and manufacture process and to the chemical etching process. $\mathrm{Vb}$ can be calculated by using several methods, such as the decrease in the detector thickness method, the loss of the detector weight method or the fission-fragment diameter method [3]-[5].

It was theoretically established that change in the mass of the detector $\Delta m$ and the density of the detector ma- 
terial is one of the main factors to measure the bulk etch rate [6].

$$
V_{B}=\frac{\Delta m}{2 A \rho t}
$$

where $\Delta m$ is mass difference; $A$ is the etched surface area; $\rho$ is the density of the detector and $t$ is the etching time.

And a "peel-off" method has been proposed by Nikezic and Janicijevic to directly measure the bulk etch rate for the LR-115 detector based on surface profile measurements using an instrument called (Taylor Hobson, Leicester, England) [7].

Another method to measure $V_{B}$ is the track of high gamma dose on the response of PADC detector (CR-39) [8].

$$
V_{B}=\frac{D_{f}}{2 t}
$$

Also $V_{B}$ could be measured by another method; and it is by measuring the track diameters $D$, and the track lengths Le (Le-D) method [9] [10].

$$
V_{B}=\frac{D^{2}}{4 t L_{e}}\left[1+\sqrt{1+\frac{4 L_{e}^{2}}{D^{2}}}\right]
$$

Another method has been proposed to determine the track etch rate by taking the relation between the etching time and the track diameters.

\section{Experiment}

The values of the tracks diameters of alpha particles in CR-39 detector and the etching time have been found by using TRACK_TEST program [11] from Yu et al. function [12] and from Brun et al. function [13] for the same energies of alpha particles (3.0, 3.6, 4.0 and 5.0) $\mathrm{MeV}$ for the two functions.

\section{Results and Discussion}

There are two methods to find the bulk etch rate for the used detector; it can be found either by irradiating it with charged particles or without irradiating it with those particles in the methods of measuring the $V_{B}$.

A simple method proposed to find the bulk etch rate in one hour for the used detector by using the following equation.

$$
V_{B}=\frac{d}{t}
$$

Figures 1-4 show the relationship between the etching time and the diameters of alpha particles in CR-39 detector for different energies of alpha particles (3.0, 3.6, 4.0 and $5.0 \mathrm{MeV}$ ) that have been obtained from Yu et al. function in TRACK_TEST program, from the figures a linear relationship has been shown between the etching times and the track diameters of alpha particles (linear increasing of the diameter with the etching process).

The bulk etch rate $V_{B}$ can be found for one hour by applying Equation (4) on the linear relationship curve for each energy.

Also Figures 5-8 show the relationship between the etching time and the diameters of alpha particles in CR-39 detector for different energies of alpha particles (3.0, 3.6, 4.0 and 5.0 MeV) that have been obtained from Brun et al. function in TRACK_TEST program, from the figures a linear relationship has been shown between the etching times and the track diameters of alpha particles.

The bulk etch rate $V_{B}$ can be found for one hour by applying Equation (4) on the linear relationship curve for each energy.

It could be seen from the Table 1 that the bulk etch rate $V_{B}$ is independent on energies of $\alpha$-particles and the values of $V_{B}$ are around $1.705 \mu \mathrm{m} / \mathrm{hr}$ for the time-diameter measurements that obtained by using Yu et al. function and $1.72 \mu \mathrm{m} / \mathrm{hr}$ for the time-diameter measurements that obtained by Brun et al. function.

These values are rather close to the value of $V_{B}$ obtained by the method of Le-D and the method of measuring the thickness of the removed layer as which has been proved by (Al-Nia'emi and Kasim, 2013) [14] and the value of $V_{B}$ is $1.7 \mu \mathrm{m} / \mathrm{hr}[15]$ and the value of $V_{B}$ is $1.95 \mu \mathrm{m} / \mathrm{hr}$ [16]. 


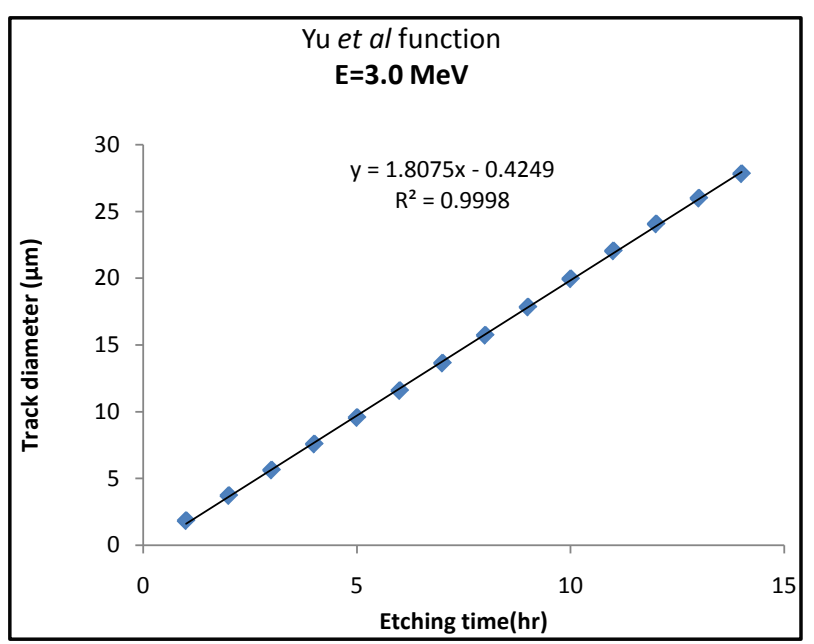

Figure 1. Track diameter $(d)$ as a function of etching time $(t)$ for alpha energy $\mathrm{E} \alpha=3.0 \mathrm{MeV}$ by using Yu et al. function.

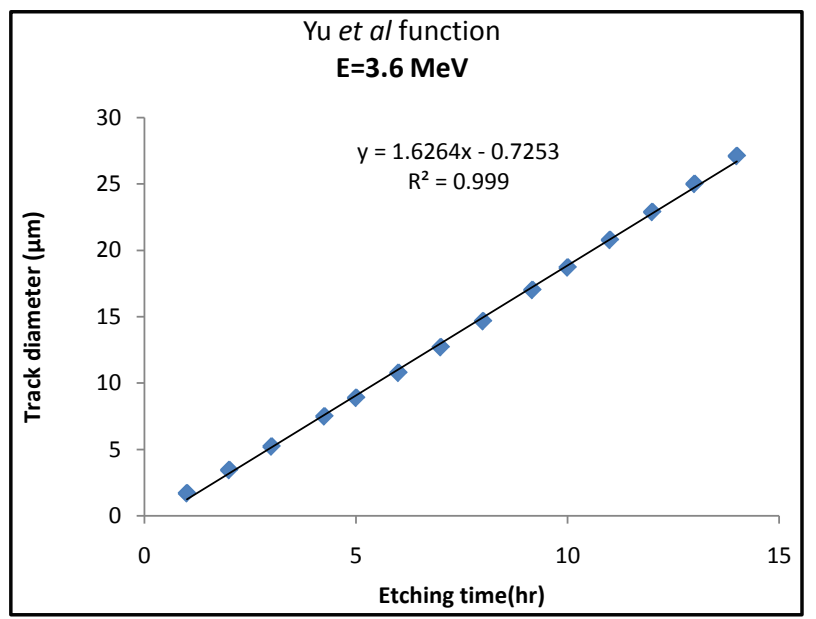

Figure 2. Track diameter $(d)$ as a function of etching time $(t)$ for alpha energy $\mathrm{E} \alpha=3.6 \mathrm{MeV}$ by using Yu et al. function.

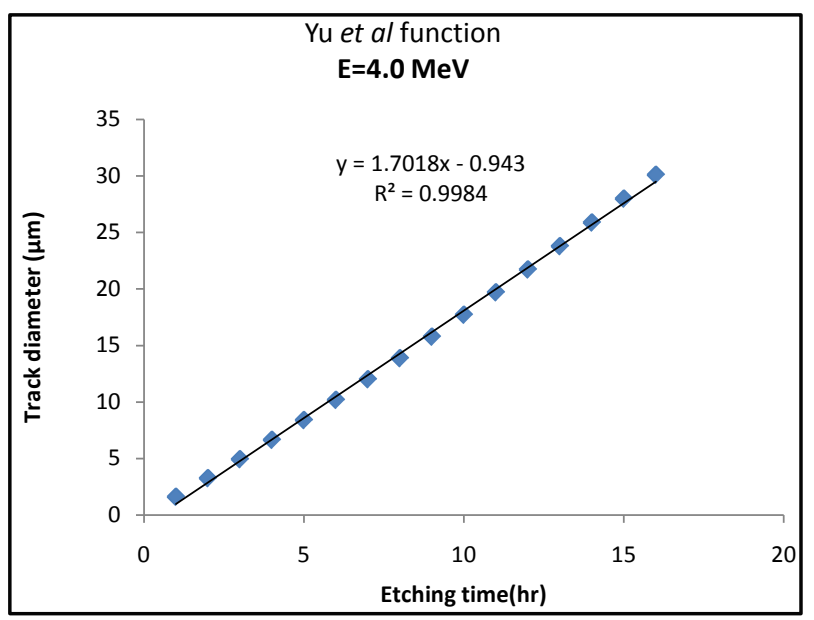

Figure 3. Track diameter $(d)$ as a function of etching time $(t)$ for alpha energy $\mathrm{E} \alpha=4.0 \mathrm{MeV}$ by using Yu et al. function. 


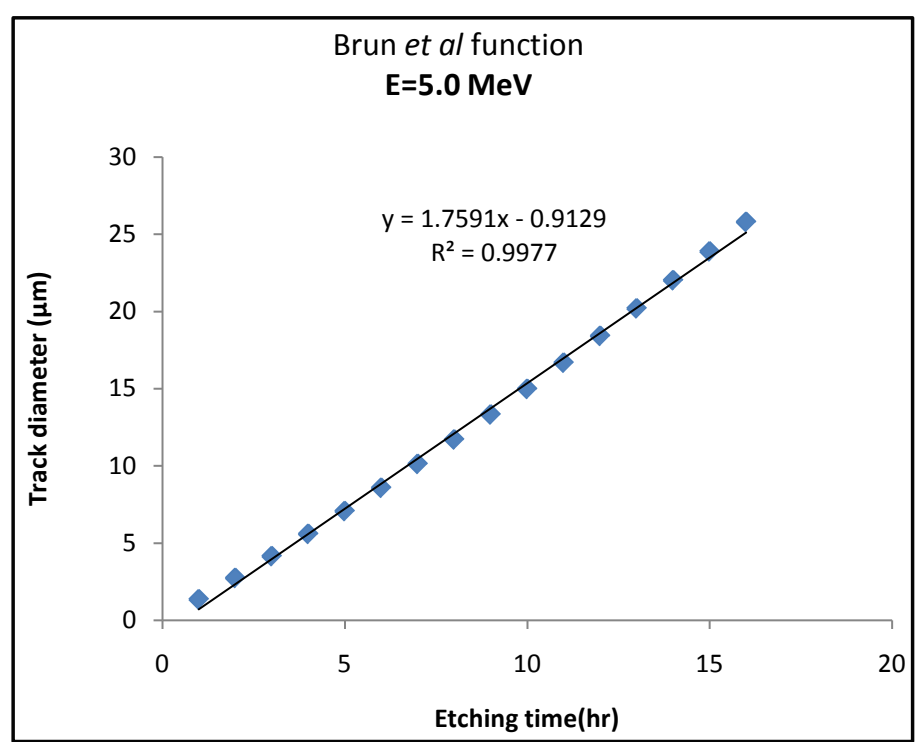

Figure 4. Track diameter $(d)$ as a function of etching time $(t)$ for alpha energy $\mathrm{E} \alpha=5.0 \mathrm{MeV}$ by using $\mathrm{Yu}$ et al. function.

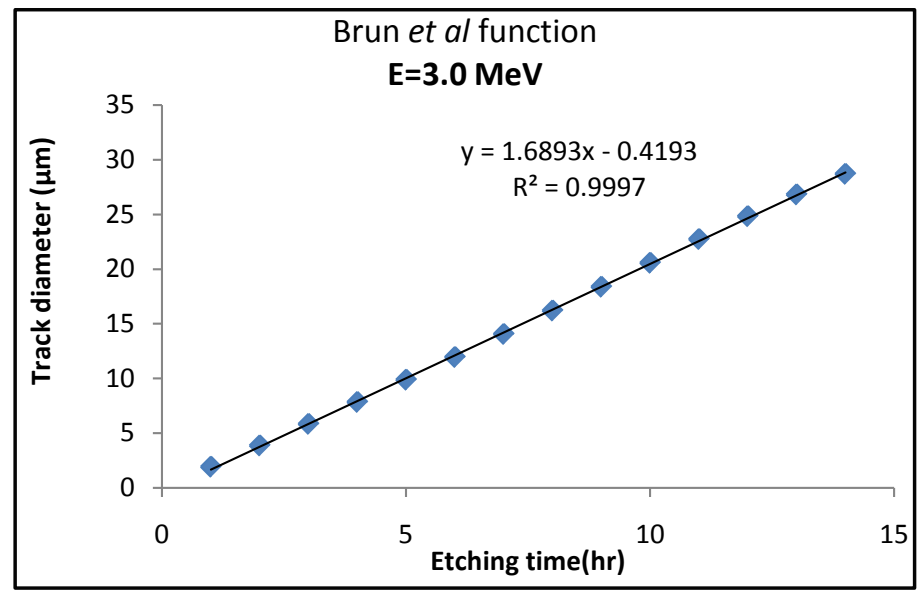

Figure 5. Track diameter $(d)$ as a function of etching time $(t)$ for alpha energy $\mathrm{E} \alpha=3.0 \mathrm{MeV}$ by using Brun et al. function.

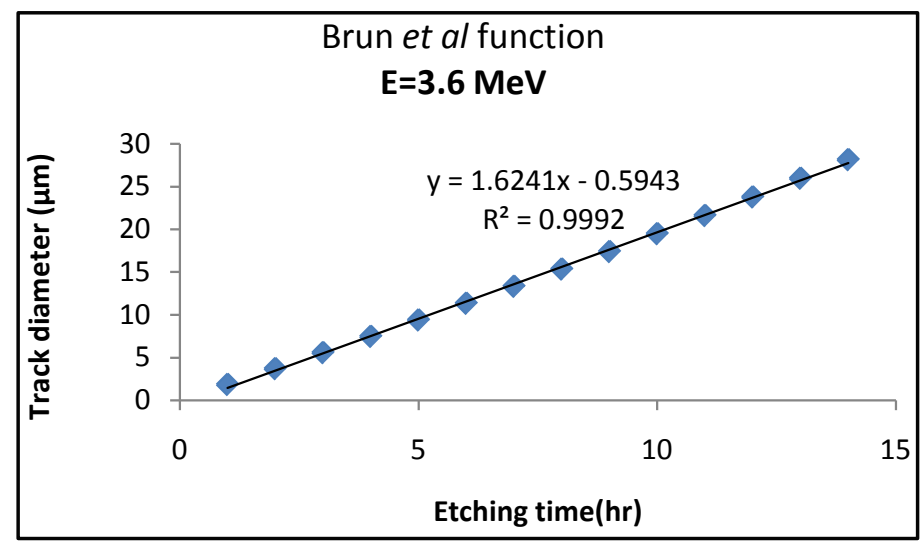

Figure 6. Track diameter $(d)$ as a function of etching time $(t)$ for alpha energy $\mathrm{E} \alpha=3.6 \mathrm{MeV}$ by using Brun et al. function. 


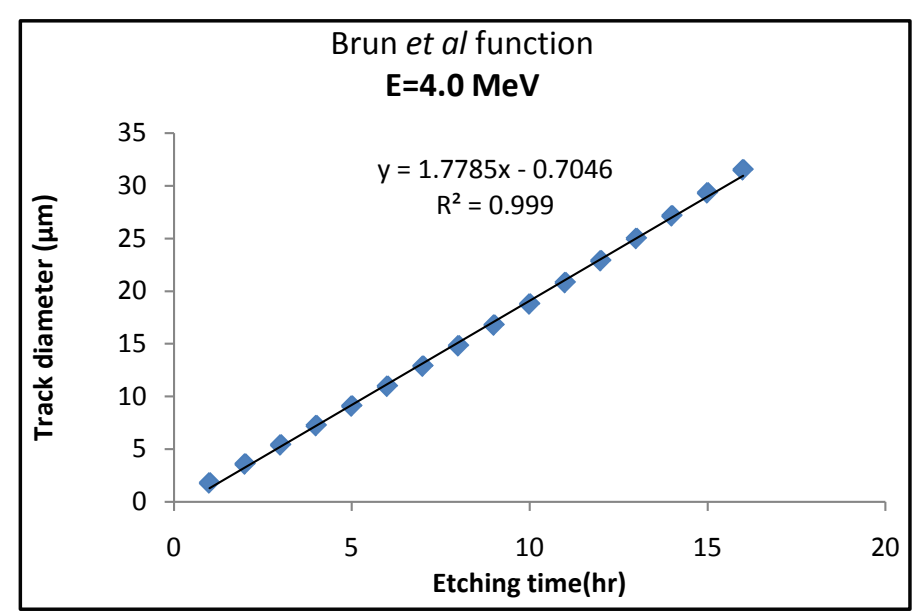

Figure 7. Track diameter $(d)$ as a function of etching time $(t)$ for alpha energy $\mathrm{E} \alpha=4.0 \mathrm{MeV}$ by using Brun et al. function.

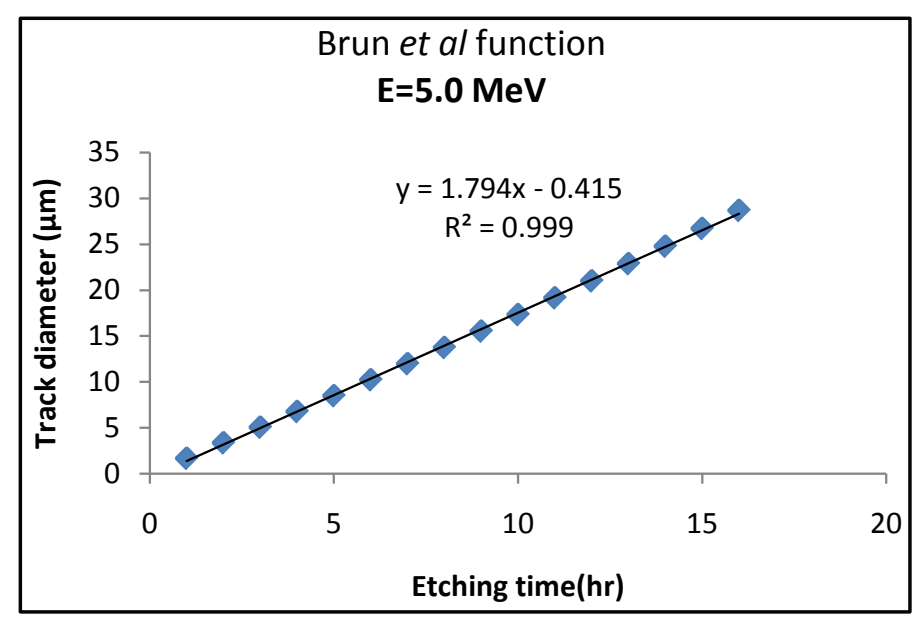

Figure 8. Track diameter $(d)$ as a function of etching time $(t)$ for alpha energy $\mathrm{E} \alpha=5.0 \mathrm{MeV}$ by using Brun et al. function.

Table 1. The values of the bulk etch rate $(\mu \mathrm{m} / \mathrm{hr})$ of CR-39 detector for different values of $\alpha$-particle energy by using timediameter measurement.

\begin{tabular}{ccc}
\hline & \multicolumn{2}{c}{ The bulk etch rate $(\mu \mathrm{m} / \mathrm{hr})$} \\
\cline { 2 - 3 } E $(\mathrm{MeV})$ & Yu et al. & Brun et al. \\
\hline 3.0 & 1.8075 & 1.6893 \\
3.6 & 1.6264 & 1.6241 \\
5.0 & 1.7018 & 1.7785 \\
5.0 & 1.7591 & 1.7947 \\
\hline
\end{tabular}

\section{Conclusion}

From the obtained results, we conclude that the time-diameter $(t-d)$ method gives good results of the bulk etch rate $\left(V_{B}\right)$, and it is a simple method because it requires getting diameters of the tracks in the detector. It was found that the results of $V_{B}$ that were measured by using the time-diameter method close to the values were measured by using the other methods. Also the bulk etch rate does not depend on energy of the particles which used to irradiate the detector. 


\section{References}

[1] Fleischer, R.L., Price, P.B. and Walker, R.M. (1975) Nuclear Tracks in Solids.

[2] Jain, R.K., Kumar, A., Chakraborty, R.N. and Nayak, B.K. (2014) Irradiation Effect of ${ }^{60}$ Co Gamma Rays on Bulk Etch Rate, Track Etch Rate and Activation Energy of CR-39 Solid State Nuclear Track Detector. Proceedings of the DAE Symposium on Nuclear Physics, 59, 432-433.

[3] Hafez, A.F. and Somogyi, G. (1986) Determination of Radon and Thoron Permeability through Some Plastics by Track Technique. International Journal of Radiation Applications and Instrumentation. Part D. Nuclear Tracks and Radiation Measurements, 12, 697. http://dx.doi.org/10.1016/1359-0189(86)90682-5

[4] Leonardi, F., Caresana, M., d’Alessandro, M., Mishra, R., Tonnarini, S., Trevisi, R. and Veschetti, M. (2009) An Extended Study of the Etching Characteristics of CR-39 Detectors. Radiation Measurements, 44, 787-790. http://dx.doi.org/10.1016/j.radmeas.2009.10.026

[5] Chavan, V., Kalsi, P.C. and Mhatre, A. (2011) The Etching, Optical and Thermal Response of a Newly Developed Nuclear Track Detector Called NADAC-ADC Copolymer to Gamma-Irradiation. Journal of Radioanalytical and Nuclear Chemistry, 87, 273-276. http://dx.doi.org/10.1007/s10967-010-0673-7

[6] Durrani, S.A. and Bull, R.K. (1987) Solid State Nuclear Track Detection. Pergamon Press, Oxford.

[7] Nikezic, D. and Janicijevic, A. (2002) Bulk Etching Rate of LR-115 Detectors. Applied Radiation and Isotopes, 57, 275-278. http://dx.doi.org/10.1016/S0969-8043(02)00109-4

[8] Salman, T.M. (2010) The Effect of Stirring and Interruption on the Etching Characteristic of cr-39 Track Detector. Journal of Basrah Researches (Sciences), 36, 17-21.

[9] Manzoor, S. (2006) Nuclear Track Detectors for Environmental Studies and Radiation Monitoring. Physical Department, University of Bologna, Bologna.

[10] Balestra, S., Cozzi, M., Giacomelli, G., Giacomelli, R., Giorgini, M., Kumar, A., Mandrioli, G., Manzoor, S., Margiotta, A.R., Medinaceli, E., Partizii, L., Popa, V., Qureshi, I.E., Rana, M.A., Sirri, G., Spurio, M., Togo, V. and Valieri, C. (2007) Bulk Etch Rate Measurements and Calibrations of Plastic Nuclear Track Detectors. Nuclear Instruments and Methods in Physics Research, B254, 254-258. http://dx.doi.org/10.1016/j.nimb.2006.11.056

[11] Nikezic, D. and Yu, K.N. (2006) Computer Program TRACK_TEST for Calculating Parameters and Plotting Profiles for Etch Pits in Nuclear Track Materials. Computer Physics Communications, 174, 160-165. http://dx.doi.org/10.1016/j.cpc.2005.09.011

[12] Yu, K.N., Ng, F.M.F. and Nikeic, D. (2005) Measuring Depths of Sub-Micron Tracks in a CR-39 Detector from Replicas Using Atomic Force Microscopy. Radiation Measurements, 40, 380-383. http://dx.doi.org/10.1016/j.radmeas.2005.03.011

[13] Brun, C., Fromm, M., Jouffroy, M., Meyer, P., Groetz, J.E., Abel, F., Chambaudet, A., Dorschel, B., Hermsdorf, D., Bretschneider, R., Kadner, K. and Kunhe, H. (1999) Inter Comparative Study of the Detection Characteristics of the CR-39 SSNTD for Light Ions: Present Status of the Besancon-Dresden Approaches. Radiation Measurement, 31, 8998. http://dx.doi.org/10.1016/S1350-4487(99)00102-X

[14] Al-Nia'emi, S.H.S. and Kasim, Y.Y. (2013) Determination of the Bulk Etch Rate of the Nuclear Track Detector CR-39 Using Le-D Method. Journal of Physics, 6, 17-25.

[15] Yu, K.N., Ng, F.M.F. and Nikeic, D. (2005) Measuring Depths of Sub-Micron Tracks in a CR-39 Detector from Replicas Using Atomic Force Microscopy. Radiation Measurements, 40, 380-383. http://dx.doi.org/10.1016/j.radmeas.2005.03.011

[16] Fromm, M., Vaginay, F., Meesen, G., Chambaudet, A. and Poffijn, A. (2003) Watching at the Correlation between the Specific Track-Etch Rate and the Primary Physical Parameters of the Swift Ion Interaction with the CR-39. Radiation Measurements, 36, 93-98. http://dx.doi.org/10.1016/S1350-4487(03)00101-X 